\title{
Conjunctival Pyogenic Granuloma after Strabismus
}

\section{Surgery}

\author{
Shinji Makino* and Kozue Hozawa \\ Department of Ophthalmology, Jichi Medical University, Japan \\ *Corresponding author: Shinji Makino, MD, Shimotsuke, 3311-1 Yakushiji, Tochigi 329-0498, Japan, Tel: +81-285-58-7382; Fax: +81-285-44-8365; E-mail: \\ makichan@jichi.ac.jp \\ Received: September 01, 2014; Accepted: September 06, 2014; Published: September 08, 2014
}

A 48-year-old man presented with exotropia of his left eye. The alternative prism cover test demonstrated there was 60 prism diopter exotropia. A $9 \mathrm{~mm}$ lateral rectus muscle recession and a $7 \mathrm{~mm}$ medial rectus muscle resection were performed in his left eye. Approximately one month later, a polypoid, red, smooth-surfaced mass arose from the area overlying the original insertion of lateral rectus muscle (Figure 1A). We diagnosed this mass as pyogenic granuloma. One month after administration with topical corticosteroid drops, this mass was completely resolved (Figure 1B). There was no recurrence during the 2 years after surgery.

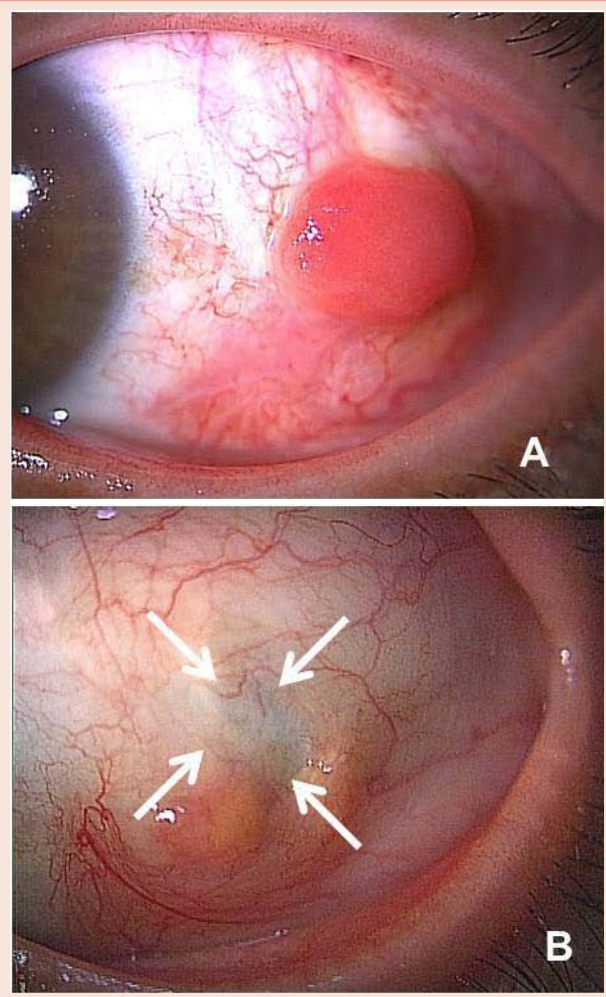

Figure A: A polypoid, red, smooth-surfaced mass arose from the area overlying the original insertion of lateral rectus muscle.

Figure B: A mass was completely resolved after one month of topical corticosteroid treatment. Arrows indicate bared sclera.
Conjunctival pyogenic granulomas are a potential complication of strabismus surgery [1,2]. Espinoza and Lueder [2] reported that conjunctival pyogenic granulomas developed in $2.1 \%$ of patients after strabismus surgery. According to their report, the majority of cases underwent a conjunctival incision $8 \mathrm{~mm}$ from the limbus. Although the present case underwent a limbal incision, en bloc recession with Tenon capsule and lateral rectus muscle was required because of large amount recession. Therefore the sclera had to be bared at the end of surgery. We speculate that pyogenic granuloma might be developed from the above bared sclera (Figure 1B, arrows).

Conservative management with topical corticosteroids is usually successful, with surgical excision being effective in those patients whose lesions do not resolve with topical medication. Furthermore, appropriate conjunctival suture should be recommended to prevent pyogenic granuloma.

\section{References}

1. Gal A, France TD (1986) Granuloma formation as a complication of the posterior fixation suture operation. Arch Ophthalmol 104: 1755.

2. Espinoza GM, Lueder GT (2005) Conjunctival pyogenic granulomas after strabismus surgery. Ophthalmology 112: 1283-1286. 